\section{Ischaemic heart disease may predispose to pseudophakic cystoid macular oedema}

\begin{abstract}
Purpose Pseudophakic macular oedema (PMO) is uncommon following uncomplicated phacoemulsification and lens implantation and the cause of infrequent cases is rarely understood. This study was undertaken to determine whether a relationship exists between ischaemic heart disease (IHD) and PMO.

Methods Retrospective case note review was carried out of 177 (252 eyes) consecutive patients without pre-existing retinal disease who underwent phacoemulsification and intraocular lens implantation during a 12 month period. Patients with a post-operative best corrected visual acuity $<6 / 9$ underwent slit-lamp biomicroscopy and fluorescein angiography to identify PMO. IHD was defined on clinical and electrocardiographic grounds. The incidence of IHD was compared in patients with and without PMO and statistical analysis performed using the Fisher's exact test.

Results PMO occurred in 4 patients (6 eyes), all of whom had IHD, whereas no PMO occurred in the remaining 173 patients (246 eyes) $(p=0.04)$.

Conclusions Pseudophakic macular oedema represents an important complication following modern phacoemulsification and intraocular lens implantation and is associated significantly with ischaemic heart disease.
\end{abstract}

Key words Ischaemic heart disease, Macular odema, Maculopathy, Phacoemulsification, Pseudophakic macular oedema

R. Jain

J.D. Stevens

C.V. Bunce

C. Garrett

P.G. Hykin

Moorfields Eye Hospital

London, UK

Rajni Jain, MRCOphth Moorfields Eye Hospital City Road

London EC1V 2PD, UK

Received: 9 February 2000 Accepted in revised form: 8 June 2000
RAJNI JAIN, JULIAN D. STEVENS, CATY V. BUNCE, CLIFF GARRETT, PHILIP G. HYKIN

between the two groups. ${ }^{5}$ PMO following uncomplicated phacoemulsification is rare, one study reporting 0 of 100 eyes with clinical PM0, although there was angiographic disease in $18 \%{ }^{6}$

The aetiology of PMO is uncertain but hypotheses include direct mechanical traction on the macula by vitreous, ${ }^{7}$ the incidence being higher following vitreous loss, ${ }^{8}$ post-operative persistent iridocyclitis ${ }^{9}$ and lens removal allowing the posterior diffusion of prostaglandins to the macula. ${ }^{10,11}$ PMO has been shown to occur more frequently in diabetes $^{12}$ and in eyes with blue rather than brown irides. ${ }^{9}$ It is more common in the Caucasian than black population ${ }^{9}$ and occurs infrequently in children undergoing $\mathrm{ECCE}^{13,14}$ unless associated with an anterior viitrectomy. Hypertension has been cited as a potential risk factor for PMO. ${ }^{15}$ This paper describes a possible association between PMO and ischaemic heart disease.

\section{Method}

Retrospective casenote review of patients who underwent phacoemulsification and lens implantation performed during a 12 month period under one consultant (J.D.S.) at Moorfields Eye Clinic, Ealing, London was performed. Data recorded included age, sex, race, best-corrected visual acuity before and after surgery, pre-existing ocular abnormality and operative details. Exclusion criteria were:(i) pre-existing macular disease, (ii) diabetes with or without retinopathy, (iii) central or branch retinal vein occlusion, (iv) amblyopia, (v) dense corneal scarring that precluded adequate fundal examination, (vi) operative complications, e.g. vitreous loss and (vii) patients under 18 years.

Clinically significant PMO was defined as post-operative best corrected visual acuity $<6 / 9$ due to retinal thickening in the macula detected by slit-lamp biomicroscopy using a 60 dioptre lens and confirmed by fluorescein angiography. Ischaemic heart disease (IHD) was defined as: (i) evidence of ischaemic damage on the preoperative electrocardiogram (ECG), as 
Table 1. Visual acuity and PMO in the patients with IHD

\begin{tabular}{|c|c|c|c|c|c|c|c|c|c|}
\hline \multirow[b]{2}{*}{ Case no. } & \multirow{2}{*}{$\begin{array}{l}\text { Pre- } \\
\text { operative } \\
\text { BSCVA }\end{array}$} & \multicolumn{5}{|c|}{ Post-operative BSCVA } & \multirow{2}{*}{$\begin{array}{l}\text { Clinical } \\
\text { PMO } \\
\text { present }\end{array}$} & \multirow{2}{*}{$\begin{array}{l}\text { Angiographic } \\
\text { PMO } \\
\text { present }\end{array}$} & \multirow[b]{2}{*}{ Treatment } \\
\hline & & Day 1 & Day 10 & Day 30 & Day 90 & Day 180 & & & \\
\hline \multicolumn{10}{|l|}{ Case 1} \\
\hline Right eye & $6 / 36$ & $6 / 9$ & $6 / 6$ & $6 / 18$ & $6 / 18$ & $6 / 12$ & Yes & Yes & $\begin{array}{l}\text { Topical steroids } \\
\text { and NSAIDs }(3 / 12)\end{array}$ \\
\hline Left eye & $6 / 60$ & $6 / 12$ & $6 / 24$ & $6 / 24$ & $6 / 24$ & $6 / 24$ & Yes & Tes & $\begin{array}{l}\text { Topical steroids } \\
\text { and NSAIDs }(3 / 12)\end{array}$ \\
\hline \multicolumn{10}{|l|}{ Case 2} \\
\hline Left eye & $6 / 36$ & $6 / 9$ & $6 / 12$ & $6 / 18$ & $6 / 18$ & $6 / 12$ & Yes & Yes & $\begin{array}{l}\text { Acetazolamide } \\
(1 / 12) \text { and topical } \\
\text { steroids }(3 / 12)\end{array}$ \\
\hline \multicolumn{10}{|l|}{ Case 3} \\
\hline Right eye & $6 / 24$ & $6 / 9$ & $6 / 36$ & $6 / 36$ & $6 / 36$ & $6 / 36$ & Yes & Yes & $\begin{array}{l}\text { Topical steroids } \\
\text { and NSAIDs }(3 / 12)\end{array}$ \\
\hline Left eye & $6 / 36$ & $6 / 6$ & $6 / 12$ & $6 / 12$ & $6 / 24$ & $6 / 24$ & Yes & Yes & $\begin{array}{l}\text { Topical steroids } \\
\text { and NSAIDs }(3 / 12)\end{array}$ \\
\hline \multicolumn{10}{|l|}{ Case 4} \\
\hline Right eye & $6 / 18$ & $6 / 9$ & $6 / 12$ & $6 / 9$ & $6 / 9$ & $6 / 9$ & Yes & Yes & $\begin{array}{l}\text { Topical steroids } \\
(3 / 12)\end{array}$ \\
\hline
\end{tabular}

BSCVA, best spectacle corrected visual acuity; NSAIDS, Non-steroidal anti-inflammatory drops.

determined by a consultant cardiologist masked to the ophthalmic diagnosis, (ii) a clinical history of IHD and (iii) both.

In all cases, the operative procedure was planned sutureless phacoemulsification with a $3.2 \mathrm{~mm}$ clear corneal pocket incision. All patients had a Chiron C11UB injectable silicone lens implant. Post-operative review occurred on the day of surgery and at 3 weeks. Patients with best corrected visual acuity $<6 / 9$ were examined as above for evidence of PMO with additional follow-up visits as appropriate.

The incidence of PMO was compared in patients with and without IHD and statistical analysis performed using the Fisher's exact test.

\section{Results}

Retrospective analysis of 290 casenotes excluded 113 patients from our cohort due to either operative complications or coexisting disease. The latter included (i) diabetic retinopathy ( $n=51)$, (ii) age-related macular degeneration $(n=33)$, (iii) dense trachoma $(n=7)$, (iv) significant myopic degeneration $(n=6),(\mathrm{v})$ amblyopia in the operated eye $(n=3)$, (vi) full-thickness macular holes $(n=2)$, (vii) previous macula-off retinal detachment $(n=1)$, (viii) benign intracranial hypertension $(n=1)$.

Patients with operative complications included 8 of 290 who had vitreous loss during surgery and 1 who had a large posterior capsular plaque remnant which precluded adequate fundal view.

Our final cohort of 177 patients (252 eyes) contained $84(46 \%)$ with evidence of IHD and 4 (6 eyes) developed PMO. The age range in our final group was 30-98 years; the mean age in the IHD group was 71 years and in the non-IHD group was 70 years. Sixty-four per cent of the IHD group were hypertensive compared with $59 \%$ in the non-IHD group. The male:female ratio was 1:1.11 in the IHD group compared with 1:1.04 in the non-IHD group.

Analysis of best corrected visual acuity (VA) outcome in the IHD patients without PMO $(n=80)$ revealed VA $>6 / 5$ in $36,6 / 6-6 / 9$ in 38 and $<6 / 9$ in 6 . In patients with no evidence of IHD $(n=93)$ VA was $>6 / 5$ in $34,6 / 6-6 / 9$ in 50 and $<6 / 9$ in 9 . In both groups all those with VA $<6 / 9(n=15)$ were examined and the VA accounted for by reasons other than $\mathrm{PMO}$, including age-related macular degeneration (10 cases), optic neuropathy (2 cases) and post-operative anterior uveitis (3 cases).

Four patients ( 6 eyes) developed PMO, all of whom had evidence of IHD (Table 1). The ECG evidence was confirmed in all cases by a consultant cardiologist masked to any information regarding history, medications and ophthalmic diagnosis (Table 2). The macular oedema was diagnosed in each case at the 3 week post-operative visit (Fig. 1a). Fluorescein angiography demonstrated characteristic dye leakage

Table 2. Diagnosis of and medications of IHD

\begin{tabular}{lllll}
\hline Case no. & Age (years) & Sex & Criteria for clinical diagnosis of IHD & Systemic medications \\
\hline Case 1 & 72 & Male & ECG and history of angina & Aspirin, isosorbide mononitrate \\
Case 2 & 66 & Female & ECG and previous CABG following myocardial infarction & Aspirin \\
Case 3 & 76 & Female & ECG and history of 2 previous myocardial infarctions & Glyceryl trinitrate prn, atenolol \\
Case 4 & 62 & Male & ECG & Nil \\
\hline
\end{tabular}

CABG, Coronary artery bypass graft. 


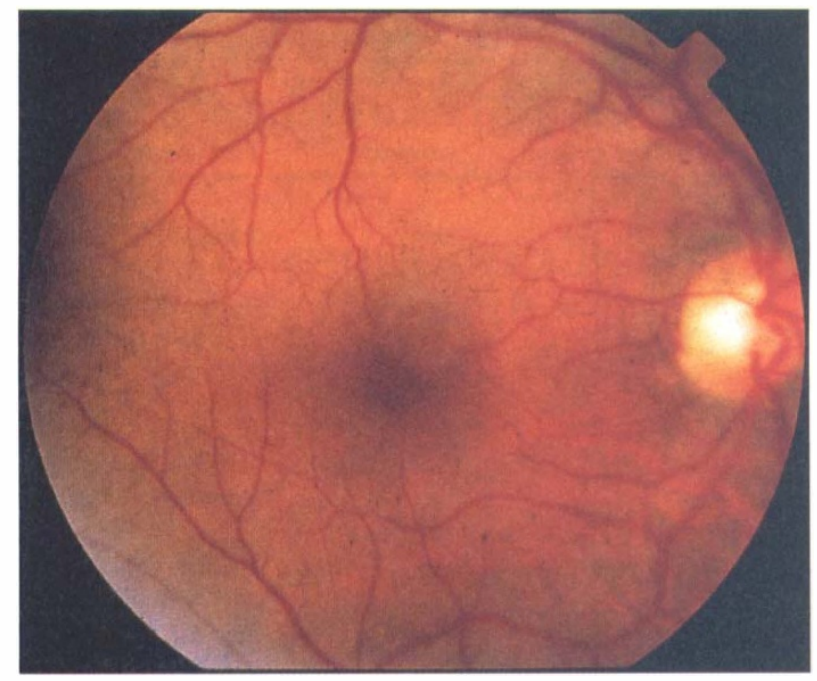

(a)
Fig 1. (a) Colour photograph demonstrating the macular oedema at the 3 week post-operative visit. (b) Fluorescein angiogram

demonstrating characteristic dye leakage from the perifoveal capillaries. (c) Petaloid leakage at the macula and disc hyperfluorescence in the late frames of the fluorescein angiogram.

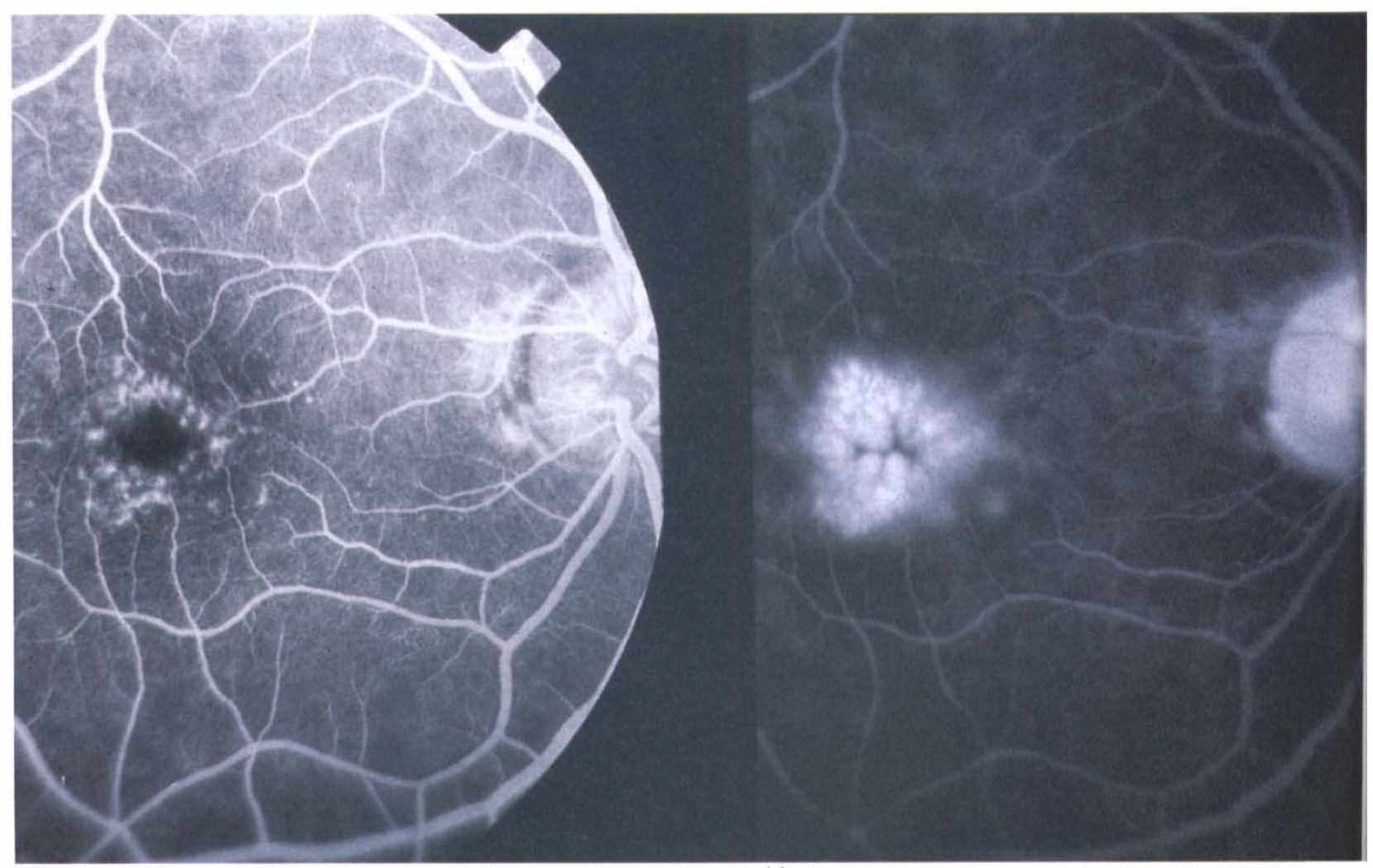

(b)

from the perifoveal capillaries in the transient phase followed by petaloid macular leakage and disc hyperfluorescence in the late frames (Fig. 1b, c).

Statistical analysis comparing the incidence of PMO in patients with and without IHD revealed an association between IHD and PMO $(p<0.04)$.

\section{Discussion}

This study suggests a relationship between pseudophakic macular oedema (PMO) and ischaemic heart disease (IHD), 4 patients with IHD developing PMO compared with no unaffected patients $(p<0.04)$. That 2 of the cases were bilateral and cases with coexisting retinal disease or complicated surgery were excluded, makes a chance association unlikely. The timing, moderate reduction in visual acuity, clinical and angiographic features and outcome were all consistent with classic PMO.

Our patient cohort consisted of all cataract operations taking place at a district general hospital (Ealing) under the care of one consultant (J.D.S.) during a 1 year period There were no tertiary referrals and all patients were placed without prioritisation on a routine local anaesthetic waiting list.

The exact pathogenesis of PMO remains unclear, and may be multifactorial. Factors likely to be important include post-operative inflammation with a concomitant disturbance in the blood-aqueous barrier, vitreomacular traction and changes in the fluid dynamics in the retinal 
perifoveal capillaries. Other possible aetiological factors include increasing age ${ }^{16}$ systemic vascular disease including hypertension and diabetes, ${ }^{17}$ relative hypotony following surgery, ${ }^{18}$ ultraviolet light exposure and some types of intraocular lens implant. 19,20

Clinical observations that suggest a role for postoperative inflammation include the presence of aqueous cells and flare in eyes with PMO, that cystoid macular oedema is associated with many inflammatory disorders including pars planitis, idiopathic vitritis, sarcoidosis and Behçet's disease, ${ }^{21,22}$ and fluorescein angiography studies showing perifoveal capillary dilatation and leakage consistent with an inflammatory process.

Supportive laboratory evidence includes the findings of inflammatory cells in vitreous aspirates ${ }^{23}$ from PMO patients and retinal phlebitis ${ }^{24}$ in gross histopathology sections taken after death. Finally, studies have shown the benefit of anti-inflammatory medication in the management of PMO.

Inflammation in PMO is believed to result from breakdown of the blood-aqueous barrier, which presumably becomes compromised secondary to direct iris trauma, altered aqueous fluid dynamics over the surface of the iris, or a combination of these.

Vitreomacular traction has been implicated in the pathogenesis of $\mathrm{PMO}^{25}$ because unilateral cases in which vitreous loss or vitreous wick syndrome is present make up over $50 \%$ of unilateral cases and there is frequently a good response to lysis of the vitreous wick. Histological evidence shows vitreous traction producing cystic retinal spaces and macular holes in some PMO cases.

PMO ultimately occurs as a result of distortion in the perifoveal capillary network disturbance leading to fluid accumulation largely in the outer plexiform layer. The likelihood of developing PMO depends on the dynamics of forces acting on perifoveal capillaries and the competency of the blood-retinal barrier. Oedema will occur if fluid filtration exceeds the rate of removal from the extracellular space. Increased filtration is favoured by high precapillary hydrostatic pressure and breakdown of the blood-retinal barrier, and removal reduced if plasma protein levels are low or retinal tissue compliance which is typically high is reduced. Although retinal autoregulation prevents an increase in capillary blood flow, there is evidence of impairment in hypertension and diabetes and this perhaps explains the increased incidence of PMO in these disorders. Thirty-six of 48 patients in one study ${ }^{1}$ of PMO had evidence of systemic hypertension and 4 others had cardiovascular disease. Whilst there is an increased incidence of IHD in patients with hypertension, it may be that autoregulation is impaired in IHD due to a failure of the precapillary arteriole to respond to autoregulatory signals. However, there is no direct evidence for this of which we are aware. In addition patients with IHD do not have significantly low serum total protein levels or recognised abnormalities of the blood-ocular barrier or even blood-brain barrier that might predispose them to PMO. In summary, whilst capillary fragility, in both the iris and retina, may be increased in patients with IHD predisposing to breakdown of the blood-aqueous barrier and blood-retinal barriers, direct evidence is lacking.

This study has implications for the prophylaxis and management of PMO. We do not routinely use NSAIDs to prevent PMO. Whilst there is good evidence that they are effective both as prophylactic agents and in the treatment of established cases, ${ }^{26}$ and that they reduce the degree and duration of blood-aqueous barrier breakdown, the incidence of clinically significant PMO after uncomplicated phacoemulsification and lens implantation, is so low $(<2.5 \%$ in this study) that routine prophylaxis seems hard to justify. However, we would now recommend their prophylactic use in patients with pre-existing hypertension or cardiovascular disease including IHD. In addition they are indicated in any patient undergoing second eye cataract surgery in whom the first eye developed PMO after surgery. Furthermore, we would recommend their post-operative use to treat any patient who develops PMO, of whatever cause, in the first few weeks after surgery.

\section{References}

1. Gass JDM, Norton EDW. Follow up study of cystoid macular edema following cataract extraction. Trans Am J Acad Ophthalmol Otolaryngol 1969;73:665-82.

2. Hitchings RA, Chisholm IH. Incidence of aphakic macular oedema;. a prospective study. Br J Ophthalmol 1975;59:444-50.

3. Severin TD, Severin SL. Pseudophakic cystoid macular oedema: a revised comparison of the incidence with intracapsular and extracapsular extraction. Ophthalmic Surg 1988;19:116-8.

4. Jaffe NS, Clayman HM, Jaffe MS. Cystoid macular oedema after intracapsular and extracapsular cataract extraction with and without an intraocular lens. Ophthalmology 1982;89:25-9.

5. Stark WJ, Maumenee AE, Fagadau W, et al. Cystoid macular edema in pseudophakia. Surv Ophthalmol 1984;28:442-51.

6. Ursell PG, Spalton DG. The incidence of cystoid macular oedema following phakoemulsification. Presented at UKCRS, 1988.

7. Schubert HD. Cystoid macular edema. The apparent role of mechanical factors. Prog Clin Biol Res 1989;312:277-91.

8. Frost NA, Sparrow JM, Strong NP, Rosenthal AR. Vitreous loss in planned extracapsular cataract extraction does lead to a poorer visual outcome. Eye 1995;9:446-51.

9. Gass JDM. Stereoscopic atlas of macular diseases. St Louis: Mosby, 1977:478-486.

10. Kraff MC, Sanders DR, Jampol LM, et al. Effect of primary capsulotomy with extracapsular surgery on the incidence of pseudophakic cystoid macular edema. Am J Ophthalmol 1984;98:166-70.

11. Wright PL, Wilkinson CP, Balyeat HD, et al. Angiographic cystoid macular edema after posterior chamber lens implantation. Arch Ophthalmol 1988;106:740-4.

12. Pollack A, Leiba H, Bukelman A, Oliver M. Cystoid macular oedema following cataract extraction in patients with diabetes. Br J Ophthalmol 1992;76:221-4.

13. Gilbard SM, Peyman GA, Goldberg MF. Evaluation for cystoid maculopathy after pars plicata lensectomy-vitrectomy for congenital cataracts. Ophthalmology 1983;90:1201-6.

14. Poer DV, Helveston EM, Ellis FD. Aphakic cystoid macular edema in children. Arch Ophthalmol 1981;99:249-52. 
15. Gass JD, Norton EWD. Follow up study of cystoid macular oedema following cataract extraction. Trans Am Acad Ophthalmol Otolaryngol 1969;73:665-82.

16. Irvine AR. Cystoid maculopathy. Surv Ophthalmol 1979;21:1-17.

17. Taylor DM, Sachs SW, Stern AL. Aphakic cystoid macular edema: longterm clinical observations. Surv Ophthalmol 1984;28:437-41.

18. Gehring JR. Macular edema following cataract extraction. Arch Ophthalmol 1968;80:626-31.

19. Junge J. Cystoid macular edema associated with PVP coating of an intraocular lens. Am Intraoc Implant Soc J 1980;6:28-9.

20. Kraff MC, Sanders DR, Jampol LM, et al. Effect of ultravioletfiltering intraocular lens on cystoid macular edema. Ophthalmology 1985;92:366-9.
21. Smith RE, Godfrey WA, Kimura SJ. Complications of chronic cyclitis. Am J Ophthalmol 1976;82:277-82.

22. Sanders MD. Retinal vasculitis: a review. J R Soc Med 1979;72:908-15.

23. Federman JL, Annesley WH Jr, Sarin LK, et al. Vitrectomy and cystoid macular edema. Ophthalmology 1980;87:622-8.

24. Martin NF, Green WR, Martin LW. Retinal phlebitis in the Irvine-Gass syndrome. Am J Ophthalmol 1977;83:377-86.

25. Schepens CL, Avila MP, Jalkh AE, et al. Role of the vitreous in cystoid macular edema. Surv Ophthalmol 1984;28:499-504.

26. Miyake K. Indomethacin in the treatment of postoperative cystoid macular edema. Surv Ophthalmol 1984;28:554-68. 